\title{
Allelic frequency of PON1 Q192R, CYP2C19*2 and CYP2C19*17 among Jordanian patients taking clopidogrel
}

\author{
Malek Rjoub ${ }^{1}$, Akram Saleh ${ }^{2}$, Nancy Hakooz ${ }^{3}$, Amer Imraish ${ }^{4}$, Yazun Jarrar ${ }^{5}$, \\ Malek Zihlif ${ }^{1 \star}$ \\ ${ }^{1}$ Department of Pharmacology, Faculty of Medicine, ${ }^{2}$ Department of Internal Medicine, University of Jordan Hospital, \\ ${ }^{3}$ Department of Biopharmaceutics and Clinical Pharmacy, Faculty of Pharmacy, ${ }^{4}$ Department of Biology, Faculty of Science, \\ The University of Jordan, ${ }^{5}$ Department of Pharmacy, College of Pharmacy, AlZaytoonah University of Jordan, Amman, Jordan
}

*For correspondence: Email: M.zihlif@ju.edu.jo; Tel: +962-6-5355000

\begin{abstract}
Purpose: To investigate the influence of allelic frequencies of PON1 Q192R, CYP2C19*2 and CYP2C19*17 genetic polymorphisms on the response to clopidogrel among Jordanian patients.

Methods: Polymorphisms in CYP2C19 were assessed among 148 patients using PCR-RFLP assay. Results: The CYP2C19*2, CYP2C19*17, and PON1 Q192R allele frequencies were 9.8, 28.72 and $28.7 \%$, respectively. On the genotyping side, the frequencies of CYP2C19*1/1* and CYP2C19*1/2* were 80.4 and $19.6 \%$, respectively, but none of the patients had CYP2C19*2/2* genotype. The genotype frequencies CYP2C19*17 were 47.97, 46.62 and $5.41 \%$ for wild-type $C$-C, heterozygote $C$ - $T$, and the mutant $T-T$, respectively. PON1 genotype was $42.7 \%$ for QQ, and $57.8 \%$ for $Q R$. None of the patients had RR genotype.

Conclusion: Relative to other populations, the observed allelic frequencies are consistent with the values reported for Caucasian and Middle Eastern populations.
\end{abstract}

Keywords: CYP2C9 polymorphisms, Clopidogrel, Genotype, Allele frequency, PON1 genes

\begin{abstract}
This is an Open Access article that uses a funding model which does not charge readers or their institutions for access and distributed under the terms of the Creative Commons Attribution License (http://creativecommons.org/licenses/by/4.0) and the Budapest Open Access Initiative (http://www.budapestopenaccessinitiative.org/read), which permit unrestricted use, distribution, and reproduction in any medium, provided the original work is properly credited.

Tropical Journal of Pharmaceutical Research is indexed by Science Citation Index (SciSearch), Scopus, International Pharmaceutical Abstract, Chemical Abstracts, Embase, Index Copernicus, EBSCO, African Index Medicus, JournalSeek, Journal Citation Reports/Science Edition, Directory of Open Access Journals (DOAJ), African Journal Online, Bioline International, Open-J-Gate and Pharmacy Abstracts
\end{abstract}

\section{INTRODUCTION}

Cytochrome 2C19 (CYP2C19) is responsible for the metabolism of many drugs such as smephenytoin, proton pump inhibitors (PPIs), clopidogrel and proguanil [1]. Genetic variants play a crucial role in inter-individual variations in response to drugs [1]. Recent studies have shown that CYP2C19 polymorphisms lead to differences in response to clopidogrel. The CYP2C19 gene is highly polymorphic in humans [2]. In the literature, more than 30 genetic variants of CYP2C19 have been described. The most frequent SNPs are CYP2C19*2 and CYP2C19*3 which cause complete absence of enzymatic activity in vitro and in vivo [3].

Another common alteration that results in multiple active alleles leading to increased activity of the enzyme is CYP2C19*17 [3]. Consequently, humans can be divided, according to the ability to metabolize CYP2C19 substrates, into poor, 
intermediate, extensive, and ultrarapid metabolizers. Poor metabolizers (PMs) have two non-functioning alleles, whereas the intermediate metabolizers (IMs) have one functioning allele. Extensive metabolizers (EMs) carry two functioning alleles, while the ultra-rapid metabolizers are characterized by having a gain-in-function variant (CYP2C19*17) that enhances CYP2C19's activity [4].

Many studies have reported that PM patients who have CYP2C19*2 loss-of-function allele are associated with marked decrease in platelet response to clopidogrel, and hence increased cardiovascular events [4]. On the other hand, patients carrying the CYP2C19*17 allele with UM phenotype may have higher benefit from clopidogrel treatment after acute myocardial infarction [5]. The CYP2C19*2 SNP has been reported to account for approximately $12 \%$ of variations in responses to clopidogrel [5]. This has indeed attracted researchers to look for other genetic factors that may account for the remaining variabilities in response to clopidogrel. Subsequently, it was revealed that the enzyme activity of paraoxonase-1 (PON1) has a strong link with clopidogrel bio-activation [6]. Moreover, PON1 is the first enzyme that catalyzes the second stage in clopidogrel bio-activation process [6]. These observations are consistent with the observed decreases in plasma paraoxonase activity, the maximum concentrations of active clopidogrel metabolites, and the increases in percentage of platelet inhibition in patients with $Q Q$ genotype.

The present study was carried out to determine the allelic frequency of PON1 Q192R, CYP2C19*2, and CYP2C19*17 among Jordanian patients on clopidogrel therapy. The findings might help in predicting the frequency of patients at risk of inadequate treatment with clopidogrel and those who may need dose adjustments.

\section{EXPERIMENTAL}

\section{Sample collection}

Whole venous blood ( $3-5 \mathrm{~mL}$ ) was collected in EDTA tubes from 148 unrelated Jordanian patients who were taking clopidogrel (55 females and 95 males). The ethical committee of the University of Jordan gave approval for this study (IRB no. 2011-35-2) which complied to the guidelines of Declaration of Helsinki [7]. All patients signed informed consent before collecting blood samples.

\section{DNA extraction}

The extraction of DNA was done using Wizard DNA extraction kit (Promega, Madison, WI, USA) according to the manufacturer's instructions.

\section{Genotyping method}

The PCR-RFLP method was carried out to determine the genotype of CYP2C19*2, *17 and PON1 as described previously [8-10], with minor modifications. In essence, the $50-\mu \mathrm{L}$ PCR reaction contained $200 \mathrm{ng}$ DNA, $10 \mu \mathrm{L}$ Taq polymerase buffer, $0.2 \mathrm{mM}$ dNTPs, $1.0 \mu \mathrm{L} \mathrm{MgCl}_{2}$, 10 picomole of the forward and reverse primers (Table 1), and $1 \mathrm{U}$ of Taq polymerase. The reaction mixtures were incubated in PCR tubes at $94{ }^{\circ} \mathrm{C}$ for $8 \mathrm{~min}$, followed by 30 cycles at $94{ }^{\circ} \mathrm{C}$ for $30 \mathrm{sec}$, and then at 63,56 or $52^{\circ} \mathrm{C}$ for $30 \mathrm{sec}$ (CYP2C19*17 *2, *17 and PON1 polymorphisms, respectively).

\section{Restriction enzyme analysis}

The PCR products for CYP2C19*2, *17 and PON1 were digested with appropriate restriction enzymes (Smal, $A L w l$ and Nsil, respectively), and the DNA fragments were separated onto 3.0 $\%$ agarose gel stained with ethidium bromide.

\section{Statistical analysis}

The CYP2C19 allele frequencies were tested for Hardy-Weinberg equilibrium using Chi-square $\left(x^{2}\right)$ test. Levels were deemed significant at $p$ values less than 0.05 .

\section{RESULTS}

Table 2 shows the allele and genotype frequencies of CYP2C19*2, *17 and PON1 Q192R among 148 unrelated Jordanian patients on clopidogrel therapy. The frequencies of CYP2C19*2, *17 and PON1 Q192R variant alleles were $9.8,28.72$ and $28.7 \%$, respectively. For genotype frequency, CYP2C19*2 scored $80.4 \%$ for the ${ }^{*} 1 /{ }^{*} 1$ wild-type, $16.6 \%$ for the heterozygote ${ }^{*} 1 /{ }^{*} 2$ and $0.0 \%$ for the mutant ${ }^{*} 2 /{ }^{*} 2$ genotype. The frequencies of CYP2C19*17 genotype were 47.97, 46.62 and $5.41 \%$ for wildtype $\mathrm{C}-\mathrm{C}$, heterozygote $\mathrm{C}-\mathrm{T}$, and mutant $\mathrm{T}-\mathrm{T}$, respectively.

For PON1 Q192R, the genotype frequencies were 42.7, 57.3, $0.0 \%$ for wild-type $Q-Q$, heterozygote $\mathrm{Q}-\mathrm{R}$, and mutant $\mathrm{R}-\mathrm{R}$, respectively. The homozygous mutant allele CYP2C19*2/*2 and PON1 R192R were not detected in any of 148 patients (Table 2 ). 
Depending on the classification of CYP2C19 enzymatic activity [4], the subjects in this study were placed in 4 metabolic groups namely: poor, intermediate, extensive and ultra-rapid metabolizers (Table 3).

When compared with other populations, the observed frequencies were consistent with the values reported in Turkish, Italian, AfricanAmerican, Saudi Arabian, German, and Danish populations, but they were profoundly different from the allelic frequencies in Chinese, Koreans, and Japanese populations (Table 4).

\section{DISCUSSION}

Clopidogrel is extensively used by Jordanians. Thus, it is important to determine the allelic frequency of the SNPs that may play a role in the effectiveness of this pro-drug. This study was aimed at determination of the allelic frequency of CYP2C19*2, CYP2C19*17, and PON1 Q192R SNPs in Jordanian patients on clopidogrel therapy. The three SNPs have been shown to play major roles in the conversion of clopidogrel to its active form. Moreover, the allelic frequency of CYP2C19*2 and CYP2C19*17 may be important in patients taking other drugs that are metabolized by CYP2C19 such as anti-ulcer medications, antidepressants, and $\beta$ adrenoceptor blockers [19].

Several studies have been carried out on CYP2C19*2 and CYP2C19*17 because they are the most common alleles that result in reduced or increased CYP2C19 activity [19].

Table 1: Primer sequences used for amplification of $C Y P 2 C 19 * 2, C Y P 2 C 19^{\star} 17$, and PON1

\begin{tabular}{ll}
\hline Primer name & Sequence (5'-3') \\
\hline CYP2C19*2-F & CAACCAGAGCTTGGCATATTG \\
CYP2C19*2-R & CACAAATACGCAAGCAGTCAC \\
CYP2C19*17-F (PCR1) & GCCCTTAGCACCAAATTCTC \\
CYP2C19*17-R (PCR1) & ATTTAACCCCCTAAAAAAACACG \\
CYP2C19*17-F (PCR2) & AAATTTGTGTCTTCTGTTCTCAATG \\
CYP2C19*17-R (PCR2) & AGACCCTGGGAGAACAGGAC \\
PON1-F & TATTGTTGCTGTGGGACCTGAG \\
PON1-R & CCTGAGAATCTGAGTAAATCCACT \\
\hline
\end{tabular}

F: Forward, R: Reverse

Table 2: CYP2C19 and PON1 genotype and allele frequencies in a sample of Jordanian patients on clopidogrel therapy

\begin{tabular}{|c|c|c|c|c|}
\hline Alleles & $\begin{array}{c}\text { Number } \\
(n=148)\end{array}$ & $\begin{array}{c}\text { Genotype frequency } \\
(\%)\end{array}$ & $\begin{array}{c}\text { Allele frequency (\%) } \\
n=296\end{array}$ & $95 \% \mathrm{Cl}$ \\
\hline \multicolumn{5}{|c|}{ CYP2C19*2 } \\
\hline $1-1$ & 119 & 80.4 & \multirow{4}{*}{$9.8(2)$} & $0.0501-0.1459$ \\
\hline $1-2$ & 29 & 16.6 & & \\
\hline $2-2$ & 0 & 0 & & \\
\hline \multicolumn{4}{|c|}{ CYP2C19*17 } & \\
\hline$C-C$ & 71 & 47.97 & \multirow{3}{*}{$28.72(\mathrm{~T})$} & $0.2143-0.3601$ \\
\hline$C-T$ & 69 & 46.62 & & \\
\hline$T-T$ & 8 & 5.41 & & \\
\hline \multicolumn{5}{|l|}{ PON1 } \\
\hline$\overline{Q-Q}$ & 64 & 42.7 & \multirow{3}{*}{$28.7(\mathrm{R})$} & \multirow{3}{*}{$0.2141-0.3599$} \\
\hline$Q-R$ & 84 & 57.3 & & \\
\hline$R-R$ & 0 & 0 & & \\
\hline
\end{tabular}

Table 3: Predicted CYP2C19 phenotype based on CYP2C19*2 and CYP2C19*17 genotypes in Jordanian patients on clopidogrel therapy

\begin{tabular}{llcc}
\hline Predicted phenotype & CYP2C19 genotype & $\begin{array}{c}\text { Number of individual } \\
(\%)\end{array}$ & $\begin{array}{c}\text { 95 \% confidence } \\
\text { interval }\end{array}$ \\
\hline EM & CYP2C19*1/*1\& & $64(43.24 \%)$ & $0.3526-0.5122$ \\
Het EM/IM & CYP2C19*2/*17 & $18(12.16 \%)$ & $0.0689-0.1743$ \\
PM & $C Y P 2 C 19^{*} 1 /{ }^{*} 2$ & $0(0.00 \%)$ & $\ldots \ldots$ \\
Het UM & $C Y P 2 C 19^{*} 2 /{ }^{*} 2$ & $58(39.19 \%)$ & $0.3132-0.4706$ \\
UM & $C Y P 2 C 19^{*} 1 /{ }^{*} 17$ & $8(5.41 \%)$ & $0.0177-0.0905$ \\
\hline
\end{tabular}


Table 4: CYP2C19 and PON1 alleles in Jordanians compared with other ethnic groups

\begin{tabular}{lccc}
\hline Population & $\begin{array}{c}\text { CYP2C19*2 } \\
\text { (Reference) }\end{array}$ & $\begin{array}{c}\text { CYP2C19*17 } \\
\text { (Reference) }\end{array}$ & $\begin{array}{c}\text { PON1 Q192R } \\
\text { (Reference) }\end{array}$ \\
\hline Chinese & 24.9 & 1.2 & 64.8 \\
Turkish & {$[11]$} & {$[11]$} & {$[11]$} \\
Italian & 12.0 & $\ldots$ & 37.8 \\
& {$[12]$} & $\ldots$ & {$[12]$} \\
American-African & 11.9 & & 28.9 \\
& {$[13]$} & 21.0 & {$[13]$} \\
Saudi Arabians & 18.2 & {$[14]$} & 32.0 \\
& {$[14]$} & 25.7 & {$[14]$} \\
Japanese & 11.2 & {$[15]$} & $\ldots$. \\
German & {$[15]$} & 1.3 & 33.4 \\
& 27.9 & {$[16]$} & {$[16]$} \\
Danish & {$[16]$} & 25.5 & 27.7 \\
& 15.2 & {$[17]$} & {$[17]$} \\
Jordanians (our & {$[17]$} & 20.1 & $\ldots .$. \\
study) & 15.0 & {$[18]$} & 28.7 \\
\hline
\end{tabular}

Inter-ethnic variations in CYP2C19 polymorphism have been reported [20]. Among Jordanians, the allelic frequency of CYP2C $19 * 2$ is within the range of 12.5 to $16 \%$ $[21,22]$. These findings are not significantly different from the $9.8 \%$ allelic frequency seen in the present study. Relative to other populations, the observed frequencies are in accordance with the values reported in Turkish, Italian, African-American, Saudi Arabian, German, and Danish populations. However, they are profoundly different from the allelic frequencies in Chinese, Korean, and Japanese populations. Interestingly, the allelic frequencies in different ethnic groups were relatively high. This may imply that this detrimental mutation is relatively old and occurred before the Black, Oriental, and Caucasian racial groups split [20].

At the phenotyping level, 29 out of the 148 patients $(19.6 \%)$ were found to carry one non- functional allele, and were classified as intermediate metabolizers, with intermediate metabolizer frequency of $12.16 \%$. These are in line with earlier report among Jordanians, where the frequency of intermediate metabolizers was in the range of $18-19.2 \%[21,22]$. None of the subjects in this study had a poor metabolizer phenotype, in contrast to what was reported previously [21,22]. A possible explanation for this variation might be the differences in the methodologies used in these studies. Future studies with a larger sample should be conducted to investigate further the percentage of poor metabolizers among Jordanians.

Since the percentage of intermediate metabolizers is not negligible in Jordanians, some patients receiving clopidogrel ( $75 \mathrm{mg}$ dose) may be at higher risk for stent thrombosis. This conclusion is supported by other studies carried out on different populations which indicated that CYP2C19*2 carriers exhibited higher platelet index in a multivariate analysis, and had significantly higher cumulative 30-day incidence of stent thrombosis, when compared with wild-type CYP2C19 carriers [19,23].

Regarding CYP2C19*17, this study is the first reported attempt to determine CYP2C19*17 allele frequency in Jordanians. The allelic frequency falls within those of the African Americans and Saudi Arabians, and is profoundly higher than that of the Chinese. The CYP2C19*17 allele and genotype frequencies reported in this study indicate that a substantial percentage of Jordanians have increased activity of the CYP2C19 enzyme. The functional and clinical implications of CYP2C19*17 on various CYP2C19 substrates (omeprazole, pantoprazole, escitalopram, sertraline, voriconazole, tamoxifen, and clopidogrel) have been reported [24].

The functional effects of CYP2C19*17 are unlikely to be clinically significant except for drugs with very narrow therapeutic windows. Out of the drugs reviewed, only clopidogrel and tamoxifen may be of concern. For clopidogrel, only CYP2C19*17 homozygotes are likely to be at significantly increased risk of experiencing the effects of excessive inhibition of platelet aggregation. More recently, it was reported that CYP2C19*2 and *17 alleles have significant influences on the response to clopidogrel response [25], which indicates that CYP2C19*17 SNP is of interest in clopidogrel users as it may 
increase the risk of bleeding especially for the $5.41 \%$ that carry the homozygous activating alleles.

On PON1 Q192R, the observed allelic frequency is consistent with the Caucasian populations including German, Italian, African-American and Japanese populations. However, its allelic frequency is significantly different from that of the Chinese. These findings indicate that there is a high degree of inter-ethnic variations in $P O N 1 Q 192 R$, and like CYP2C19*2, this SNP is relatively old and probably occurred before the racial groups were split.

With respect to PON1 Q192R phenotype and clopidogrel metabolism, none of the study subjects was an extensive metabolizer. However, 86 patients had intermediate metabolizer phenotype. Moreover, an appreciable number of subjects (12.2\%) combined both CYP2C19*2 and PON1Q192 SNPs. It is speculated that this may put them at higher risk for thrombosis than those with only one non-functioning allele of either CYP2C19 or PON1.

Although clopidogrel is activated mainly by PON1 enzyme [6], subsequent studies reported contradictory outcomes by excluding any significant role for PON1 enzyme in the activation of clopidogrel [8]. Accordingly, a prospective study should be conducted to clarify the involvement of PON1 in the activation of clopidogrel. Considering the fact that the variation in CYP2C19*2 frequencies accounted for only $12 \%$ of the observed variability in clopidogrel response, these studies are direly needed [2].

\section{CONCLUSION}

Compared with other populations, the observed CYP2C19*2, *17 and PON1 allelic frequencies are in accordance with the values reported for Caucasian and Middle Eastern populations. Further intensive studies are needed to unravel the influence of CYP2C19*2, ${ }^{*} 17$ and PON1 polymorphisms on clinical clopidogrel response.

\section{DECLARATIONS}

\section{Acknowledgement}

This research was supported by a grant from the Deanship of Academic Research at The University of Jordan. All aspects of this work were carried out at The University of Jordan.

\section{Conflict of interest}

The authors declare that no conflict of interest is associated with this work.

\section{Contribution of authors}

We declare that this work was done by the authors named in this article and all liabilities pertaining to claims relating to the content of this article will be borne by the authors. Malek Rjoub did most of the laboratory work, with some assistance from Amer Imraish. He also wrote manuscript. Akram Saleh collected the blood samples from University of Jordan Hospital. Nancy Hakooz. Malek Zihlif supervised the work and reviewed the manuscript. Yazun Jarrar did the technical review.

\section{REFERENCES}

1. Frueh FW, Amur S, Mummaneni P, Epstein RS, Aubert RE, DeLuca TM, Verbrugge RR, Burckart GJ, Lesko LJ. Pharmacogenomic biomarker information in drug labels approved by the United States food and drug administration: prevalence of related drug use. Pharmacotherapy 2008; 28(8): 992-998.

2. Shuldiner AR, O'Connell JR, Bliden KP, Gandhi A, Ryan $K$, Horenstein RB, Damcott CM, Pakyz R, Tantry US, Gibson $Q$, et al. Association of cytochrome P450 2C19 genotype with the antiplatelet effect and clinical efficacy of clopidogrel therapy. JAMA 2009; 302(8): 849-857.

3. Sibbing $D$, Koch $W$, Gebhard D, Schuster T, Braun $S$, Stegherr J, Morath $T$, Schomig A, von Beckerath $N$, Kastrati A. Cytochrome 2C19*17 allelic variant, platelet aggregation, bleeding events, and stent thrombosis in clopidogrel-treated patients with coronary stent placement. Circulation 2010; 121(4): 512-518.

4. Scott SA, Sangkuhl K, Gardner EE, Stein CM, Hulot JS, Johnson JA, Roden DM, Klein TE, Shuldiner AR, Clinical Pharmacogenetics Implementation C. Clinical Pharmacogenetics Implementation Consortium guidelines for cytochrome P450-2C19 (CYP2C19) genotype and clopidogrel therapy. Clin Pharmacol Ther 2011; 90(2): 328-332.

5. Collet JP, Hulot JS, Pena A, Villard E, Esteve JB, Silvain $J$, Payot L, Brugier D, Cayla G, Beygui $F$, et al. Cytochrome $P 450$ 2C19 polymorphism in young patients treated with clopidogrel after myocardial infarction: a cohort study. Lancet 2009; 373(9660): 309-317.

6. Bouman HJ, Schomig E, van Werkum JW, Velder J, Hackeng CM, Hirschhauser C, Waldmann C, Schmalz HG, ten Berg JM, Taubert D. Paraoxonase-1 is a major determinant of clopidogrel efficacy. Nat Med 2011; 17(1): 110-116.

7. World Medical A. World Medical Association Declaration of Helsinki: ethical principles for medical research 
involving human subjects. JAMA 2013; 310(20): 2191 2194.

8. Trenk $D$, Hochholzer W, Fromm MF, Zolk O, Valina CM, Stratz C, Neumann FJ. Paraoxonase-1 Q192R polymorphism and antiplatelet effects of clopidogrel in patients undergoing elective coronary stent placement. Circ Cardiovasc Genet 2011; 4(4): 429-436.

9. Anichavezhi D, Chakradhara Rao US, Shewade DG, Krishnamoorthy $R$, Adithan $C$. Distribution of CYP2C19*17 allele and genotypes in an Indian population. J Clin Pharm Ther 2012; 37(3): 313-318.

10. Jarrar $Y B$, Balasmeh $A A$, Jarrar $W$. Sequence analysis of the $N$-acetyltransferase 2 gene (NAT2) among Jordanian volunteers. Libyan J Med 2018; 13(1): 1408381.

11. Chen L, Qin S, Xie J, Tang J, Yang L, Shen W, Zhao X, $\mathrm{Du} \mathrm{J}$, He G, Feng G, et al. Genetic polymorphism analysis of CYP2C19 in Chinese Han populations from different geographic areas of mainland China. Pharmacogenomics 2008; 9(6): 691-702.

12. Aynacioglu AS, Sachse $C$, Bozkurt A, Kortunay S, Nacak M, Schroder T, Kayaalp SO, Roots I, Brockmoller J. Low frequency of defective alleles of cytochrome $P 450$ enzymes 2C19 and 2D6 in the Turkish population. Clin Pharmacol Ther 1999; 66(2): 185-192.

13. Scordo MG, Caputi AP, D'Arrigo C, Fava G, Spina E. Allele and genotype frequencies of CYP2C9, CYP2C19 and CYP2D6 in an Italian population. Pharmacol Res 2004; 50(2): 195-200.

14. Luo HR, Poland RE, Lin KM, Wan YJ. Genetic polymorphism of cytochrome P450 2 C19 in Mexican Americans: a cross-ethnic comparative study. Clin Pharmacol Ther 2006; 80(1): 33-40.

15. Saeed LH, Mayet AY. Genotype-phenotype analysis of CYP2C19 in healthy Saudi individuals and its potential clinical implication in drug therapy. Int J Med Sci 2013; 10(11): 1497-1502.

16. Sugimoto $K$, Uno $T$, Yamazaki H, Tateishi T. Limited frequency of the CYP2C19*17 allele and its minor role in a Japanese population. $\mathrm{Br} J$ Clin Pharmacol 2008; 65(3): 437-439.

17. Geisler T, Schaeffeler E, Dippon J, Winter S, Buse V, Bischofs C, Zuern C, Moerike K, Gawaz M, Schwab M. CYP2C19 and non-genetic factors predict poor responsiveness to clopidogrel loading dose after coronary stent implantation. Pharmacogenomics 2008; 9(9): 1251-1259.

18. Pedersen RS, Brasch-Andersen C, Sim SC, Bergmann TK, Halling J, Petersen MS, Weihe $P$, Edvardsen $H$, Kristensen VN, Brosen $K$, et al. Linkage disequilibrium between the CYP2C19*17 allele and wildtype CYP2C8 and CYP2C9 alleles: identification of CYP2C haplotypes in healthy Nordic populations. Eur J Clin Pharmacol 2010; 66(12): 1199-1205.

19. Lee SJ. Clinical Application of CYP2C19 Pharmacogenetics Toward More Personalized Medicine. Front Genet 2012; 3: 318.

20. Goldstein JA, Ishizaki T, Chiba K, de Morais SM, Bell D, Krahn PM, Evans DA. Frequencies of the defective CYP2C19 alleles responsible for the mephenytoin poor metabolizer phenotype in various Oriental, Caucasian, Saudi Arabian and American black populations. Pharmacogenetics 1997; 7(1): 59-64.

21. Yousef AM, Bulatova NR, Newman W, Hakooz N, Ismail S, Qusa H, Zahran F, Anwar Ababneh N, Hasan F, Zaloom $I$, et al. Allele and genotype frequencies of the polymorphic cytochrome P450 genes (CYP1A1, CYP3A4, CYP3A5, CYP2C9 and CYP2C19) in the Jordanian population. Mol Biol Rep 2012; 39(10): 94239433.

22. Zalloum I, Hakooz N, Arafat T. Genetic polymorphism of CYP2C19 in a Jordanian population: influence of allele frequencies of CYP2C19*1 and CYP2C19*2 on the pharmacokinetic profile of lansoprazole. Mol Biol Rep 2012; 39(4): 4195-4200.

23. Frere C, Cuisset T, Morange PE, Quilici J, Camoin-Jau L, Saut N, Faille D, Lambert M, Juhan-Vague I, Bonnet JL, et al. Effect of cytochrome p450 polymorphisms on platelet reactivity after treatment with clopidogrel in acute coronary syndrome. Am J Cardiol 2008; 101(8): 1088-1093.

24. Li-Wan-Po A, Girard T, Farndon P, Cooley C, Lithgow J. Pharmacogenetics of CYP2C19: functional and clinical implications of a new variant CYP2C19*17. Br J Clin Pharmacol 2010; 69(3): 222-230.

25. Cuisset T, Morange PE, Quilici J, Bonnet JL, Gachet C, Alessi MC. Paraoxonase-1 and clopidogrel efficacy. Nat Med 2011; 17(9): 1042-1034. 